\title{
ARTICLE
}

\section{Absorption spectroscopic observation of interactions between neptunium and oxide ions in molten LiCl-KCl eutectic}

\author{
Tae-Hong Park ${ }^{\mathrm{a}, \mathrm{b}^{*}}$, Dae-Hyeon Kim ${ }^{\mathrm{a}}$, Sang-Eun Bae ${ }^{\mathrm{a}, \mathrm{b}}$, Jong-Yun Kim ${ }^{\mathrm{a}, \mathrm{b}}$ and Young-Hwan Cho ${ }^{\mathrm{a}}$ \\ ${ }^{a}$ Nuclear Chemistry Research Division, Korea Atomic Energy Research Institute, 989-111 Daedeok-daero, Yusung-gu, Daejeon \\ 34057, Korea; ${ }^{b}$ Department of Radiochemistry and Nuclear Nonproliferation, University of Science and Technology, 217 \\ Gajeong-ro, Yuseong-gu, Daejeon 34113, Korea
}

\begin{abstract}
Understanding the chemical and electrochemical behavior of oxide ions in the presence of actinide and lanthanide ions in molten chlorides is of key relevance to the pyroprocessing technology. In this work, we examined the reaction between $\mathrm{Np}^{4+}$ (neptunium cations) and $\mathrm{O}^{2-}$ (oxide ions) in $\mathrm{LiCl}-\mathrm{KCl}$ eutectic using $\mathrm{UV}$-visible-NIR absorption spectroscopy. $\mathrm{O}^{2-}$ is known to react with $\mathrm{Np}^{4+}$, causing precipitation of $\mathrm{NpO}_{2}$ in the $\mathrm{LiCl}-\mathrm{KCl}$ melt. However, we observed a new absorption band at $\sim 380 \mathrm{~nm}$ upon the addition of $\mathrm{Li}_{2} \mathrm{O}$ to the melt containing $\mathrm{Np}^{4+}$. We assigned this absorption signal to the $f-d$ transition of $\mathrm{Np}^{3+}$ and suggested the possible reduction or disproportionation of $\mathrm{Np}^{4+}$ in its reaction with $\mathrm{O}^{2-}$, concomitant with the precipitation of $\mathrm{NpO}_{2}$ from the melt.
\end{abstract}

Keywords: pyroprocessing; molten salt; neptunium; oxide; absorption spectroscopy

\section{Introduction}

The pyrochemical method is a promising back-end fuel cycle option to handle the accumulation of spent nuclear fuel resulted from nuclear electric power generation [1]. This approach enables electrochemical partitioning and recovery of actinides and fission products from spent nuclear fuel based on their thermodynamics. Many studies have been performed to understand the electrochemical behavior of uranium, lanthanide, and transuranium (TRU) species in high-temperature molten salt media. In addition to such understanding of the electrode reactions, comprehensive knowledge of chemical interactions between the elements present in the molten salt is important for pyroprocessing.

Oxide ion $\left(\mathrm{O}^{2-}\right)$ is a common impurity in the electrorefining process, and it is generated by impurities in metal fuel feeding [2] or contamination by traces of oxygen and moisture [3]. Therefore, understanding the interactions between actinide/lanthanide and oxide ions in the melt can improve the electrorefining process. However, studies on TRUs are relatively rare [4] as compared to those on uranium and lanthanides [2].

Absorption spectroscopy is a useful tool for the speciation and quantification of solutes in solutions. In particular, it is suitable for monitoring electrochemical and chemical reactions in corrosive, high-temperature molten salt media [5].

*Corresponding author. Email: parktae@kaeri.re.kr
In the present work, we studied the chemical reactions between neptunium and oxide ions in LiCl-KCl eutectic melts using UV-visible-NIR absorption spectroscopy. The oxidation state of neptunium was controlled electrochemically. The results showed that the reaction between $\mathrm{Np}^{4+}$ and $\mathrm{O}^{2-}$ resulted in not only the precipitation of neptunium oxide, as anticipated, but also the formation of a soluble species that exhibited an absorption band around $380 \mathrm{~nm}$.

\section{Experimental}

All experiments were carried out in a glove box filled with Ar. The oxygen content and moisture level were maintained below $1 \mathrm{ppm}$. A furnace designed for absorption and electrochemical measurements was equipped in the lower part of the glove box, as described elsewhere [6]. Electrochemical experiments were performed with a Gamry Reference 3000 potentiostat. Figure 1a shows the spectroelectrochemical cell used in this study. A rectangular quartz cell (path length: $1 \mathrm{~cm}$ ) was attached to a 350 -mm-long quartz tube and placed in the middle of the furnace. Three electrodes were carefully immersed into the $\mathrm{LiCl}-\mathrm{KCl}$ eutectic from the top, to avoid blocking of the light path. The $\mathrm{Ag} \mid \mathrm{Ag}^{+}$ reference electrode was prepared by immersing a $\mathrm{Ag}$ wire into a $\mathrm{LiCl}-\mathrm{KCl}$ eutectic melt containing $1.0 \mathrm{wt} \%$ $\mathrm{AgCl}$. The counter electrode was prepared by immersing a tungsten wire into the $\mathrm{LiCl}-\mathrm{KCl}$ eutectic melt. Both the electrodes were cased in pyrex tubes to prevent direct 
electrical contact with each other. A glassy carbon rod or a tungsten wire was used as the working electrode. Light beam from a deuterium-halogen lamp was guided by an optical fiber and directed into the sample chamber within the furnace. Then, the light beam was allowed to pass through a spectroelectrochemical cell containing the LiCl-KCl eutectic sample (Figure 1) and collimated through another optical fiber connected to a QE65 Pro spectrophotometer and an NIRQuest512 spectrometer (Ocean Optics Inc.) for the wavelength ranges of 200-990 $\mathrm{nm}$ and 900-1400 nm, respectively.

Anhydrous $\mathrm{LiCl}-\mathrm{KCl}$ eutectic beads and lithium oxide $\left(\mathrm{Li}_{2} \mathrm{O}\right)$ were obtained from Sigma-Aldrich. Lanthanum chloride and cerium chloride (purity $\geq$ 99.99\%) were purchased from Alfa Aesar. $\mathrm{Li}_{2} \mathrm{O}-\mathrm{LiCl}$, $\mathrm{LaCl}_{3}-\mathrm{LiCl}-\mathrm{KCl}$, and $\mathrm{CeCl}_{3}-\mathrm{LiCl}-\mathrm{KCl}$ pellets were prepared by dissolving $3-5 \%$ of the solutes in the corresponding melts, followed by solidification of the mixtures in thin glass tubes [2]. Np-LiCl-KCl pellets were prepared as described elsewhere [5]. Briefly, electrochemical carbochlorination of $\mathrm{NpO}_{2}^{+}$in a LiCl-KCl melt, followed by electrodeposition, afforded $\mathrm{Np}$ metal, which was then electrochemically dissolved in a fresh LiCl-KCl melt and solidified at ambient temperature in a thin glass tube. These cylindrical pellets were added to $\mathrm{LiCl}-\mathrm{KCl}$ melts for the absorption spectroscopic and electrochemical studies.
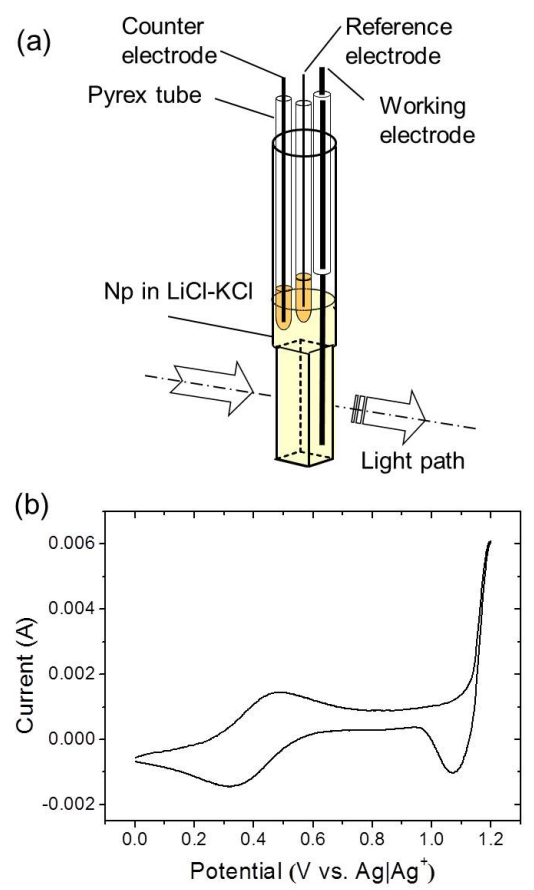

Figure 1. (a) Schematic of the spectroelectrochemical cell. (b) Cyclic voltammogram of $\mathrm{Np}^{4+}(\sim 15 \mathrm{mM})$ in $\mathrm{LiCl}-\mathrm{KCl}$ at 500 ${ }^{\circ} \mathrm{C}$

\section{Results and discussion}

Figure $1 \mathrm{~b}$ shows the cyclic voltammogram of the $\mathrm{Np}$ ion in a $\mathrm{LiCl}-\mathrm{KCl}$ melt. Anodic and cathodic peak currents appeared at 0.50 and $0.33 \mathrm{~V}$ versus $\mathrm{Ag} \mid \mathrm{Ag}^{+}$, which were attributed to the oxidation of $\mathrm{Np}^{3+}$ to $\mathrm{Np}^{4+}$ and the reduction of $\mathrm{Np}^{4+}$ to $\mathrm{Np}^{3+}$, respectively. No significant peaks other than that for chloride oxidation were observed at more positive potentials, indicating that soluble neptunyl species was not present in the melt [5].

Figure 2 displays the absorption spectra of the neptunium ions in $\mathrm{LiCl}-\mathrm{KCl}$ melts. The dissolution of the $\mathrm{Np}-\mathrm{LiCl}-\mathrm{KCl}$ pellets afforded a $\mathrm{Np}^{3+}$ complex, and electrochemical oxidation at $0.8 \mathrm{~V}$ versus $\mathrm{Ag} \mid \mathrm{Ag}^{+}$ resulted in a $\mathrm{Np}^{4+}$ complex in the melt [5]. The $\mathrm{Np}^{3+}$ complex showed a broad absorption band at $383 \mathrm{~nm}$ at a concentration of $\sim 1 \mathrm{mM}$ and the $\mathrm{Np}^{4+}$ complex showed a monotonic increase in absorbance below $500 \mathrm{~nm}$ (Figure 2a). Both $\mathrm{Np}$ complexes exhibited several discrete absorption bands at 500-1350 nm but showed much lower absorbance even at higher Np concentrations ( $\sim 4$ $\mathrm{mM}$, Figure 2b) because of their $f-f$ transition characteristics [5].
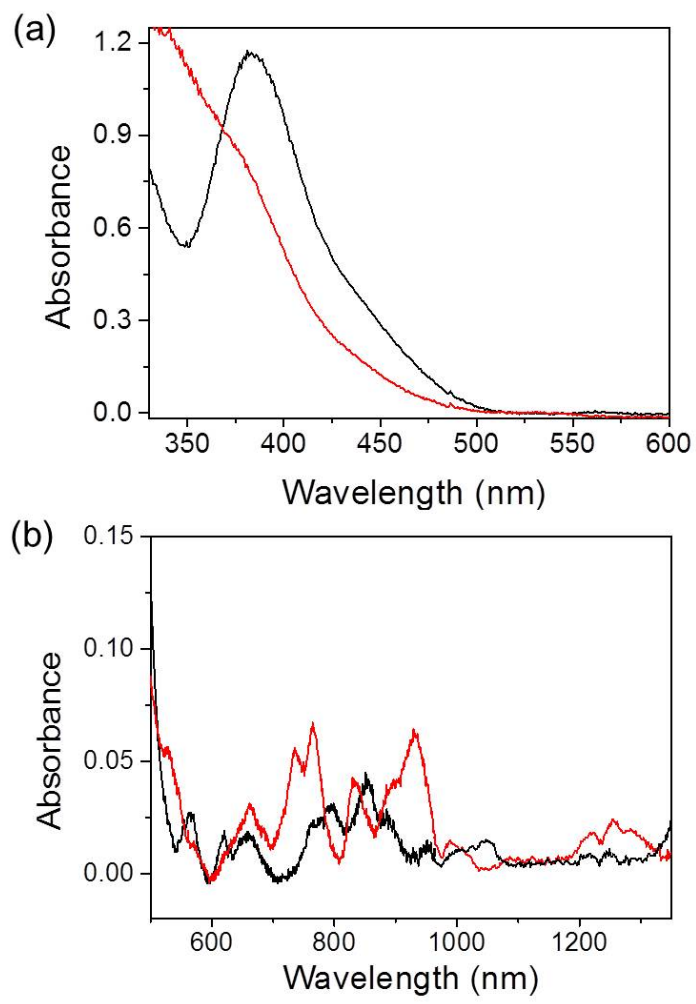

Figure 2. Electronic absorption spectra of $\mathrm{Np}^{3+}$ (black) and $\mathrm{Np}^{4+}$ (red) in LiCl-KCl at $500{ }^{\circ} \mathrm{C}$ recorded using a QEPro spectrometer (a) and after combining the spectra from a QEPro spectrometer and an NIRQuest 512 spectrometer at $970 \mathrm{~nm}$ (b). The solution concentrations were $\sim 1 \mathrm{mM}$ (a) and $\sim 4 \mathrm{mM}$ (b).

Figure 3 shows the UV-vis absorption spectra of multicomponent melts prepared by adding $\mathrm{LaCl}_{3}-\mathrm{LiCl}-\mathrm{KCl}$ and $\mathrm{CeCl}_{3}$ - $\mathrm{LiCl}-\mathrm{KCl}$ pellets to the melts containing $\mathrm{Np}^{4+}$. Interestingly, the addition of $\mathrm{LaCl}_{3}$ 
resulted in a new absorption shoulder at 350-400 nm (Figure 3a), although $\mathrm{La}^{3+}$ has no electronic transitions in the region recorded [2]. The subsequent addition of $\mathrm{CeCl}_{3}$ not only gave rise to a characteristic $f$ - $d$ transition band of $\mathrm{Ce}^{3+}$ at 300-350 nm [2], but also enhanced absorbance of the band at $\sim 380 \mathrm{~nm}$, indicating that both the lanthanide pellets probably yielded the same product after reacting with $\mathrm{Np}^{4+}$.

However, different batches of pellets led to dissimilar results in terms of appearance and intensity of the new absorption signal, which could be due to traces of impurities such as oxide in the pellets. To remove the oxide impurities, we dissolved the pellets again and treated them with electrochemically generated $\mathrm{Cl}_{2}$ gas [5]. Notably, the addition of purified lanthanide pellets to a melt containing $\mathrm{Np}^{4+}$ did not result in a significant absorption signal around $380 \mathrm{~nm}$ (Figure 3b), implying that the lanthanide oxide impurities likely reacted with $\mathrm{Np}^{4+}$ in Figure $3 \mathrm{a}$.

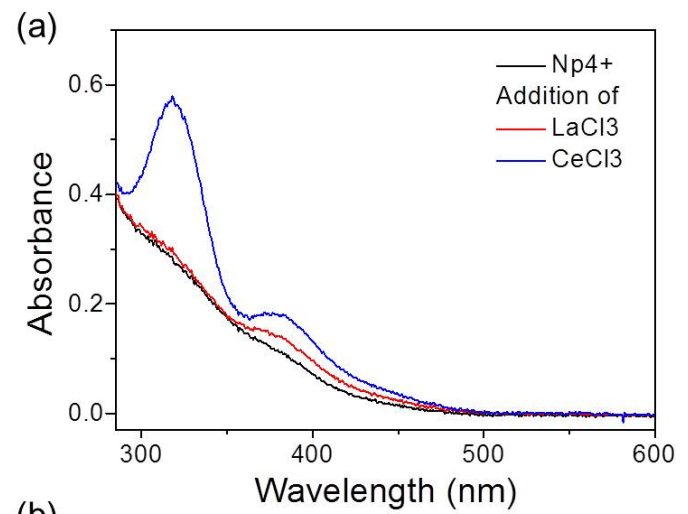

(b)

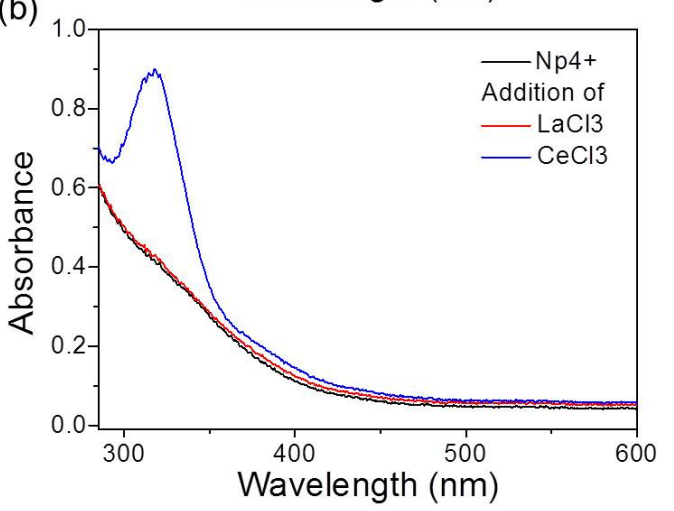

Figure 3. Electronic absorption spectra of $\mathrm{Np}^{4+}$ (black) in LiCl-KCl melts with subsequent addition of $\mathrm{LaCl}_{3}$ (red) and $\mathrm{CeCl}_{3}$ (blue) before (a) and after (b) purification of lanthanide chlorides.

The reactions of actinide and lanthanide ions with oxide ions are of interest because the oxide ions in the electrorefining salt precipitate the metal ions as metal oxychloride or metal oxide species, and thus are likely to affect pyroprocessing [2]. $\mathrm{Np}^{4+}$ is known to react with $\mathrm{O}^{2-}$ in $\mathrm{LiCl}-\mathrm{KCl}$ eutectic melt, precipitating $\mathrm{NpO}_{2}$, as described in Eq. (1) with a high $p \mathrm{~K}_{\mathrm{sp}} \sim 20$ at $660{ }^{\circ} \mathrm{C}$ [4].

$$
\mathrm{Np}^{4+}+2 \mathrm{O}^{2-} \rightarrow \mathrm{NpO}_{2}(\mathrm{~s})
$$

This leads to the assumption that $\mathrm{Np}^{4+}$ reacts with the oxide impurity in the lanthanide chloride salts to yield a soluble species concomitant with $\mathrm{NpO}_{2}$ in the LiCl-KCl melt.

In order to verify this assumption, we monitored the reaction of $\mathrm{Np}^{4+}$ and $\mathrm{O}^{2-}$ using absorption spectroscopy. Figure 4a displays the change in the absorption spectrum of $\mathrm{Np}^{4+}(\sim 0.2 \mathrm{mM})$ with the consecutive addition of $\mathrm{Li}_{2} \mathrm{O}(\sim 20 \mu \mathrm{g} \times 3)$. As observed for the lanthanide pellets, the addition of $\mathrm{Li}_{2} \mathrm{O}$ resulted in a new band at $\sim 380 \mathrm{~nm}$. However, consecutive additions of $\mathrm{Li}_{2} \mathrm{O}$ decreased the absorbance of the new band and resulted in a featureless spectrum due to the precipitation of $\mathrm{NpO}_{2}$. Interestingly, the energy of the new absorption band was very similar to that of the $f-d$ transition band of $\mathrm{Np}^{3+}$ at $383 \mathrm{~nm}$, whose high molar absorptivity probably allows $\mathrm{Np}^{3+}$, if present, to be observed even at high dilution.

Further, we investigated the $f-f$ transitions of the $\mathrm{Np}$ ions at a higher concentration $(\sim 1 \mathrm{mM})$. In Figure $4 \mathbf{b}$, the red line (iii) displays the spectrum of the reaction mixture of $\mathrm{Np}$ ions, which was obtained during the electroreduction of $\mathrm{Np}^{4+}$ (ii, blue) to $\mathrm{Np}^{3+}$ (iv, black) [5]. Therefore, the spectrum exhibited absorption features of both species. On the other hand, the pink trail (i) in Figure $4 \mathrm{~b}$ shows the spectrum obtained after adding $\mathrm{Li}_{2} \mathrm{O}(\sim 100 \mu \mathrm{g})$ to the $\mathrm{Np}^{4+}$ solution. Notably, the characteristics of spectra (i) and (iii) were similar, indicating the presence of unreacted $\mathrm{Np}^{4+}$ as well as newly formed $\mathrm{Np}^{3+}$ in the melt. Although the reaction of $\mathrm{Np}^{4+}$ and $\mathrm{O}^{2-}$ thermodynamically favors the precipitation of $\mathrm{NpO}_{2}$ (Eq. 1), the higher formal potential of $\mathrm{Np}^{3+} \mid \mathrm{Np}^{4+}(\sim 0.42 \mathrm{~V})$ compared to that of $\mathrm{O}_{2} \mid \mathrm{O}^{2-}(\sim 0.1 \mathrm{~V}$ vs. $\left.\mathrm{Ag} \mid \mathrm{Ag}^{+}\right)$in the $\mathrm{LiCl}-\mathrm{KCl}$ melt $[5,7]$ may trigger the reaction described in Eq. (2).

$$
2 \mathrm{~Np}^{4+}+\mathrm{O}^{2-} \rightarrow 2 \mathrm{~Np}^{3+}+1 / 2 \mathrm{O}_{2}
$$

Moreover, it has been reported that the disproportionation of $\mathrm{Np}^{4+}$ in a $\mathrm{RuCl}-\mathrm{CsCl}$ melt at $660-770{ }^{\circ} \mathrm{C}$ yields $\mathrm{Np}^{3+}$ and $\mathrm{NpO}_{2}^{+}$by controlling $p \mathrm{O}^{2-}$ of the solution using a $\mathrm{HCl}-\mathrm{H}_{2} \mathrm{O}$ gas mixture [8]. $\mathrm{NpO}_{2}{ }^{+}$ is not clearly evident in the spectrum (Figure $4 \mathrm{~b}-\mathrm{i}$ ), probably due to its low concentration and superimposition of transitions with $\mathrm{Np}^{3+}$ and $\mathrm{Np}^{4+}[8,9$, 10 ]. However, a disproportionation reaction, as suggested in Eq. (3), might also produce $\mathrm{Np}^{3+}$.

$$
2 \mathrm{~Np}^{4+}+2 \mathrm{O}^{2-} \rightarrow \mathrm{NpO}_{2}^{+}+\mathrm{Np}^{3+}
$$

Therefore, the absorption signals at $\sim 380 \mathrm{~nm}$ in Figures 3 and 4 could be attributed to the $f-d$ transition of $\mathrm{Np}^{3+}$ resulting from the reaction of $\mathrm{Np}^{4+}$ and $\mathrm{O}^{2-}$ in the LiCl-KCl melts. However, further studies will be carried out to unambiguously authenticate such a minor by-product or intermediate in the reaction mixture. 

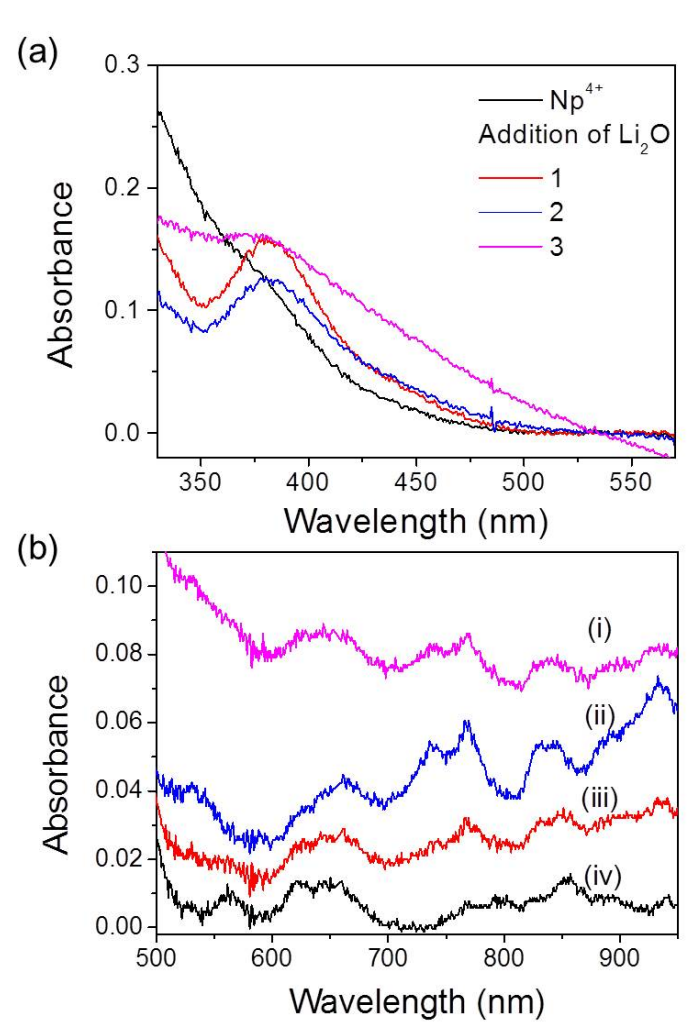

Figure 4. (a) Absorption spectra with sequential addition (1 to 3 ) of $\mathrm{Li}_{2} \mathrm{O}$ to the LiCl-KCl melt including $\mathrm{Np}^{4+}(\sim 0.2 \mathrm{mM})$. (b) Absorption spectra of a mixture of $\mathrm{Np}^{4+}$ and $\mathrm{Li}_{2} \mathrm{O}$ in a LiCl-KCl melt (i) and absorption spectra recorded while electrochemically reducing $\mathrm{Np}^{4+}$ to $\mathrm{Np}^{3+}$ in $\mathrm{LiCl}-\mathrm{KCl}$ melt for comparison: $\mathrm{Np}^{4+}$ (ii), a mixture of $\mathrm{Np}^{4+}$ and $\mathrm{Np}^{3+}$ (iii), and $\mathrm{Np}^{3+}$ (iv). [Np] $1 \mathrm{mM}$.

\section{Conclusion}

Here, we studied the reaction between $\mathrm{Np}^{4+}$ and $\mathrm{O}^{2-}$ in LiCl-KCl eutectic using absorption spectroscopy. Although $\mathrm{NpO}_{2}$ precipitation is thermodynamically favorable, we observed a new soluble species upon the addition of $\mathrm{Li}_{2} \mathrm{O}$ to the melt containing low concentrations (less than a few $\mathrm{mM}$ ) of $\mathrm{Np}^{4+}$. Interestingly, an absorption band was seen at $\sim 380 \mathrm{~nm}$, which was energetically very similar to the $f-d$ transition of $\mathrm{Np}^{3+}$. In addition, the absorption spectrum of the reaction mixture closely resembled that of a mixture of $\mathrm{Np}^{4+}$ and $\mathrm{Np}^{3+}$ prepared electrochemically. On the basis of these results, we assigned the new absorption signal to $\mathrm{Np}^{3+}$ and proposed redox reactions occurring in parallel with the precipitation reaction of $\mathrm{NpO}_{2}$.

\section{Acknowledgements}

This work was supported by National Research
Foundation of Korea (NRF) grant (2017M2A8A5014710), funded by the Korean government.

\section{References}

[1] H. Lee, G.-I. Park, K.-H. Kang, J.-M. Hur, J.-G. Kim, D.-H. Ahn, Y.-J. Cho and E.-H. Kim, Pyroprocessing technology development at KAERI, Nucl. Eng. Technol. 43 (2011), pp. 317-328.

[2] S. Choi, S.-E. Bae and T.-H. Park, Electrochemical and spectroscopic monitoring of interactions of oxide ion with $\mathrm{U}(\mathrm{III})$ and $\mathrm{Ln}(\mathrm{III})(\mathrm{Ln}=\mathrm{Nd}, \mathrm{Ce}$, and $\mathrm{La})$ in LiCl-KCl melts, J. Electrochem. Soc. 164, (2017), pp. H5068-H5073.

[3] X.K. Feng and C.A. Melendres, Anodic corrosion and passivation behavior of some metals in molten LiCl-KCl containing oxide ions, J. Electrochem. Soc. 129 (1982), pp. 1245-1249.

[4] R. Lysy, G. Duyckaerts, Diagramme potential-pO2du neptunium dans l'eutectique $\mathrm{LiCl}-\mathrm{KCl}$ a $660{ }^{\circ} \mathrm{C}$, Anal. Chim. Acta 96 (1978), pp. 125-132.

[5] D.-H. Kim, T.-H. Park, S.-E. Bae, N. Lee, J.-Y. Kim, Y.-H. Cho, J.-W. Yeon and K. Song, Electrochemical preparation and spectroelectrochemical study of neptunium chloride complexes in LiCl-KCl eutectic melts, $J$. Radioanal. Nucl. Chem. 308 (2016), pp. 21-36.

[6] Y.J. Park, S.-E. Bae, Y.-H. Cho, J.-Y. Kim and K. Song, UV-Vis absorption spectroscopic study for on-line monitoring of uranium concentration in LiCl-KCl eutectic salt. Microchem. J. 99 (2011) pp.170-173.

[7] Y. Kado, T. Goto and R. Hagiwara, Oxygen electrode reaction in a $\mathrm{LiCl}-\mathrm{KCl}$ eutectic melt, $J$. Electrochem. Soc. 156 (2009), pp. E167-E170.

[8] R. Lysy and G. Duyckaerts, Etude des reactions d'oxydo-réduction du neptunium dans le mélange RbCl-CsCl $(25-75 \%$ mol), Anal. Chim. Acta 94 (1977), pp. 385-394.

[9] R. Lysy, G. Landresse and G. Duyckaerts, Étude quantitative d'équilibres chimiques en solution dans lse sels fondus par spectrophotométrie d'absorption: Application au neptunium, Anal. Chim. Acta 72, (1974), pp. 307-314.

[10] A. Uehara, T. Nagai, T. Fujii, O. Shirai and H. Yamana, Spectrophotometric and electrochemical study of neptunium ions in molten $\mathrm{NaCl}-\mathrm{CsCl}$ eutectic, J. Nucl. Mater. 437 (2013), pp. 166-170. 